\title{
Catalyst design for highly efficient carbon dioxide hydrogenation to formic acid under buffering conditions
}

Andreas Weilhard, ${ }^{a}$ Kevin Salzmann, ${ }^{\mathrm{b}}$ Miquel Navarro, ${ }^{\mathrm{b}}$ Jairton Dupont, ${ }^{\mathrm{c}}$ Martin Albrecht, ${ }^{\mathrm{b*}}$ Victor Sans $s^{\mathrm{a}, \mathrm{d} *}$

a) Faculty of Engineering, University of Nottingham, Nottingham, NG7 2RD, UK

b) Department of Chemistry \& Biochemistry, University of Bern, Freiestrasse 3, 3012 Bern, Switzerland

c) Institute of Chemistry - UFRGS - Av. Bento Gonçalves, 9500 Porto Alegre 91501-970 - RS Brazil

d) Institute of Advanced Materials (INAM), Universitat Jaume I, 12006, Castellon, Spain

Corresponding author e-mail: sans@uji.es; martin.albrecht@dcb.unibe.ch

\section{Abstract}

We report on new ruthenium complexes as catalysts for the efficient transformation of $\mathrm{CO}_{2}$ into formic acid employing basic ionic liquids as buffering media. Remarkably, these complexes catalyze the hydrogenation of $\mathrm{CO}_{2}$ selectively and without employing strong bases, which improves the sustainability of the process when compared to common base-mediated technologies. The molecular catalyst design relies on donor-flexible and synthetically versatile pyridylidene amide (PYA) ligands which allows the ligand architecture to be varied in a controlled manner to gain valuable insights for the improvement of catalyst performance. Modification of the ligand properties directly influence the catalytic process by shifting the turnover limiting step, the reaction mechanism and the stability upon the acidification of the reaction media and provide access to high-performance systems reaching turnover numbers of several thousands and turnover frequencies up to $350 \mathrm{~h}^{-1}$. 


\section{Introduction}

The transformation of carbon dioxide $\left(\mathrm{CO}_{2}\right)$ into valuable chemicals and fuels is a key challenge of the $21^{\text {st }}$ century and has gained a lot of interest in recent years.[1, 2] Indeed, the synthesis of commodity chemicals, such as (poly)carbonates, hydrocarbons, methanol, formic acid and specialty chemicals[1] from $\mathrm{CO}_{2}$ is highly desirable, as $\mathrm{CO}_{2}$ represents a cheap, and virtually infinite source of $\mathrm{C} 1$ building blocks.[1,2] Except for the case of carbonates, $\mathrm{CO}_{2}$ has to be reduced to a lower oxidation state. As reduced and synthetically useful product, formic acid (FA) represents formally the easiest target, requiring one dihydrogen molecule to react with one molecule of $\mathrm{CO}_{2}$ to form $\mathrm{FA}$ and reducing formally the oxidation state of carbon from $+\mathrm{IV}$ to +II. Indeed the transformation of $\mathrm{CO}_{2}$ to $\mathrm{FA}$ using $\mathrm{H}_{2}$ via artificial photosynthesis has attracted high scientific and economic interest, also because $\mathrm{CO}_{2}$ reduction is environmentally much more benign compared to the current production of FA by formal water carbonylation[3] at a megaton capacity per year.[4] Furthermore, FA has potential applications as a hydrogen storage vector.[5-9]

The hydrogenation of $\mathrm{CO}_{2}$ is thermodynamically and kinetically challenging.[2] Indeed, the hydrogenation of $\mathrm{CO}_{2}$ and $\mathrm{H}_{2}$ in the gas phase to generate $\mathrm{FA}$ in liquid phase is entropically highly unfavourable and renders the reaction endergonic and the reaction in the liquid phase often poisons the catalyst due to the acidity of the reaction media.[10,11] Most commonly the thermodynamic equilibrium is shifted to the product side by the addition of stoichiometric amounts of base. Under these conditions, a plethora of noble metal catalysts have shown remarkably high activity $\left(\mathrm{TON}>10^{6}\right)$. [12] The catalysts are based on the combination of advanced ligand types such as N-heterocyclic carbenes[13, 14], half sandwich,[5, 15-17] pincers[12, 18-20] and phosphine[21-25] complexes, including also recent advances in the us of non-noble transition metals such as iron,[26-29] nickel,[30, 31] copper and cobalt.[32-34] The key step in those processes is the formation of formate salts and adducts, which shifts the thermodynamic equilibrium to the product side. This increases the enthalpy and makes the reactions highly exothermic. Nevertheless, this energy has to be overcome during 
downstream processing to be able to utilize the formate salt synthesized in the presence of stoichiometric amounts of base. Currently, major strategies involve reactive distillation[10, 35, 36] or utilization of $\mathrm{scCO}_{2}[37]$ as eluent phase to liberate formic acid from the reaction media, which is both economically and environmentally unattractive due to the energy involved as well as the huge quantities of waste produced.

In a more sustainable fashion, the reaction can be carried out in pure solvents without the addition of base. In this regard DMSO has found increased attention.[38-40] Here the basic properties of the solvent are exploited to stabilize the product by hydrogen bonding[39] and can be further enhanced by the addition of small amounts of water.[38] Furthermore, water[4143] and ionic liquids (ILs)[44-46] have demonstrated to facilitate the formation of $\mathrm{FA}$ from $\mathrm{CO}_{2}$ and $\mathrm{H}_{2}$. However, in most cases the catalytic turnover[39, 40] and concentrations of $F A$ obtained[41-43] are relatively modest, with $T O N s<1000$. Very recently, we have reported that ionic liquids can efficiently mediate the hydrogenation of $\mathrm{CO}_{2}$ to formic acid by acting as a buffer, maintaing the $\mathrm{pH}$ at a level that prevents catalyst deactivation. The counteranion plays a crucial role as acetate and formate ILs prefer the formation of formic acid, whilst with bis(trifluoromethylsulfonyl)imide ILs a preferential formation of CO has been observed.[44, 45] Indeed, in the presence of ILs the reaction can be carried out in less basic solvents including THF, MeCN and MeTHF,[45] which are easier to separate than DMSO or water by stripping due to their relatively low boiling point.

In order to improve the catalytic performance and to benefit from the clear advantages of buffered FA synthesis, we designed ruthenium complexes containing an electronically flexible pyridylidene amide (PYA) ligand.[47-49] These ligands stabilize different electronic configurations at the metal center through unique toggling between a limiting zwitterionic and neutral resonance structure (Scheme 1),[50-52] which has been found to have an important effect in redox catalysis.[53-55] Here, a set of neutral and cationic ruthenium complexes featuring PYA ligands are demonstrated to be efficient $\mathrm{CO}_{2}$ reduction catalysts and produce FA in the absence of a strong base. Kinetic analysis, electrochemistry and spectroscopic 
analyses offer valuable insights into the catalyst reactivity, stability and activity under buffering conditions and provide structure-activity relationships for the sustainable $\mathrm{CO}_{2}$ hydrogenation to formic acid.

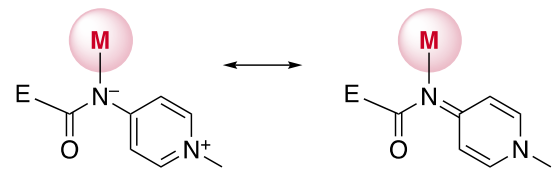

Scheme 1: Limiting resonance structures of PYA ligands featuring a zwitterionic amide (left) for stabilizing electron-poor metal centers, and the formally neutral limiting imine resonance form for stabilizing electron-rich metal centers (right); E may be a (non-)chelating functional group.

\section{Results and discussion}

\section{Synthesis of the ruthenium complexes and evaluation of their catalytic activity in $\mathrm{CO}_{2}$}

reduction. Complexes 1-3 were synthesized by reaction of the known pyridinium salts L1L3 with $\left[\mathrm{Ru}(\mathrm{cym}) \mathrm{Cl}_{2}\right]_{2}$ in the presence of $\mathrm{NaOAc}$ (Scheme 2 and see SI for details about the synthetic details).[56] This protocol afforded the cationic complex 1 containing a para-PYA ligand stabilized by a chelating pyridylidene unit in $61 \%$ yield, and the formally neutral complexes 2 and $\mathbf{3}$ in about 40\% yield. These latter complexes were also prepared stepwise from the pyridinium salt by first deprotonating the pyridinium salt to form the free pyridylidene, followed by cycloruthenation. All complexes are air- and moisture-stable solids. Coordination of the PYA ligand site was indicated by the downfield shift of the PYA proton resonances (e.g. from $=9.25\left(\mathrm{DMSO}-d_{6}\right)$ in $\mathrm{L} 3$ to $9.86\left(\mathrm{CDCl}_{3}\right)$ for $\mathrm{H} \alpha$ in complex 3$)$, and the loss of one aromatic signal with concomitant desymmetrization of the remaining resonances established successful cyclometallation, see SI. Further evidence for the formation of complexes 1-3 was obtained from a single crystal X-ray diffraction analysis, which confirmed the anticipated connectivity pattern (Scheme 2).[57]

Complex 1 containing a pyridylidene NHC ligand and a para-PYA ligand was cationic and featured an $\mathrm{OTf}^{-}$anion. Notably, the donor properties of the three chelates is reflected in the electron density at the ruthenium center, quantified by cyclic voltammetry and revealing a shift 
of the $R u^{\prime \prime} / R u^{\text {III }}$ oxidation potential from $E_{1 / 2}=+0.45 \mathrm{~V}$ (for complex 1 with a formally neutral pyridylidene-PYA chelate) to lower potential for complexes $\mathbf{2}$ and $\mathbf{3}$ with an anionic phenylPYA chelating ligand $\left(E_{1 / 2}=+0.14\right.$ and $+0.08 \mathrm{~V} v s \mathrm{Fc}^{+} / \mathrm{Fc}$, respectively; all values in $\mathrm{MeNO}_{2}$, Table S2). These data suggests stronger donor properties of the meta-PYA unit in complex 3 compared to the para-PYA analogue (complex 2), in agreement with previous studies.[54]

A)

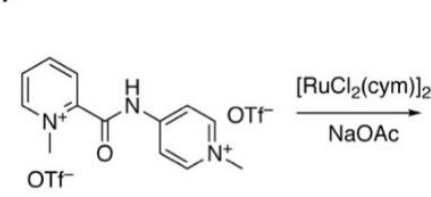

L1<smiles>O=C(Nc1ccncc1)c1ccccc1</smiles>

L2

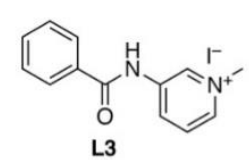

L3

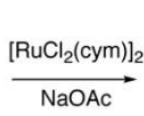

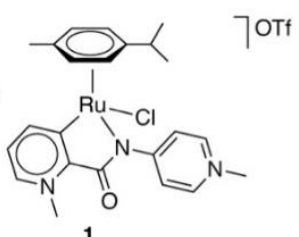

1

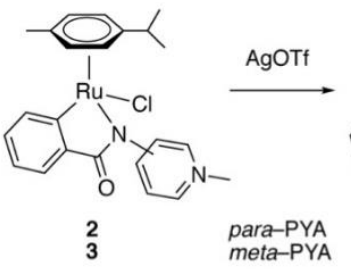

OTf
B)
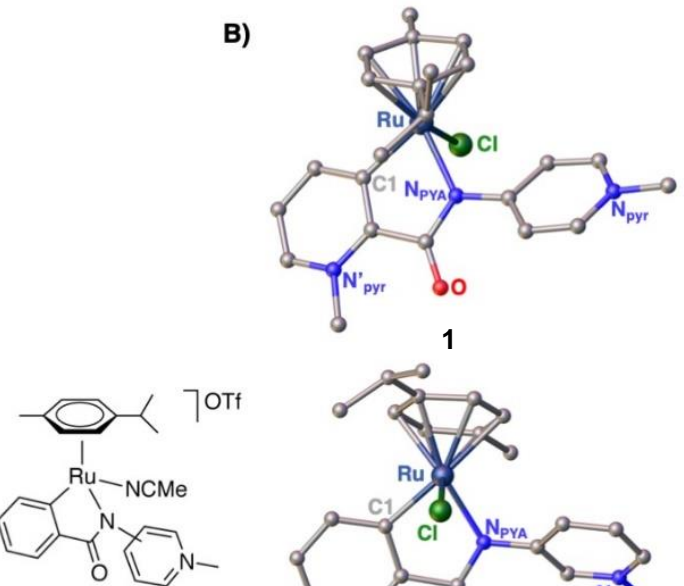

2-MeCN

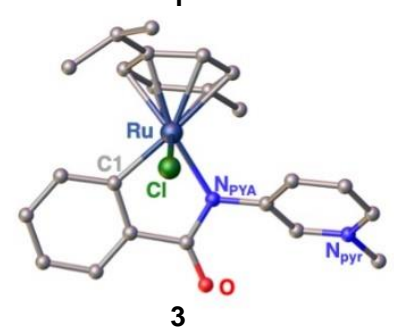

Scheme 2. A) Synthesis of complexes 1-3 and the solvent analogues 2-MeCN and 3-MeCN. B) X-ray structures of 1 and $\mathbf{3}$ (both 50\% probability thermal ellipsoids, OTf anion of $\mathbf{1}$ and all $\mathrm{H}$ atoms omitted for clarity)

The neutral complexes 2 and $\mathbf{3}$ were readily transformed into their cationic species 2-MeCN and 3-MeCN, respectively, upon halide abstraction with AgOTf in MeCN (Scheme 2). Formation of the solvent complex is accompanied by an upfield shift of the PYA H $\alpha$ protons and a downfield shift of the PYA $H \beta$ protons in 2-MeCN compared to 2. These shifts are indicative for a larger relevance of the zwitterionic vs the charge-neutral limiting resonance form, in agreement with the lower electron density at the ruthenium center when bound to a MeCN ligand vs an anionic chloride. Interestingly, cyclic voltammetry does not suggest a change of the electronic configuration at the ruthenium center and the $\mathrm{Ru} / \mathrm{R} / \mathrm{R} \mathrm{u}^{\mathrm{III}}$ redox potential 
of 2-MeCN $\left(E_{1 / 2}=0.14 \mathrm{~V}\right.$ vs $\mathrm{Fc}^{+} / \mathrm{Fc}, \mathrm{MeNO}_{2}$ solution, Table S2) is identical to that of complex

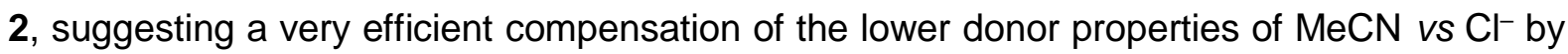
the more zwitterionic PYA resonance form (Fig S7). In contrast, CV measurements in DMSO are featureless for complex $\mathbf{2 - M e C N}$, while complex 2 reveals a shallow oxidation at low potential (Fig. S8).

For an initial evaluation of these complexes in $\mathrm{CO}_{2}$ reduction catalysis, we chose DMSO: $\mathrm{H}_{2} \mathrm{O}$ (5 $\mathrm{v} / \mathrm{v} \% \mathrm{H}_{2} \mathrm{O}$ ) as the solvent system in combination with 1-butyl-2,3-dimethylimidazolium acetate (BMMI.OAc) as an additive. Under these conditions, the ionic liquid, BMMI.OAc, acts as a buffer during the formation of formic acid or the combination of IL and water may also catalyze the formation of carbonates.[45, 58-60] Further stabilization of the product is imparted by solvent cluster formation by FA, water and DMSO.[38, 39] These are known as base-free conditions in the literature. In the presence of $\mathrm{H}_{2}$ and $\mathrm{CO}_{2}\left(\mathrm{P}\left(\mathrm{H}_{2}\right)=\mathrm{P}\left(\mathrm{CO}_{2}\right)=30\right.$ bar, $\left.\mathrm{T}=70^{\circ} \mathrm{C}\right)$, all PYA ruthenium complexes catalyze the formation of FA without the need of an additional strong base (Table 1).

Table 1 Screening of catalytic activity of complexes 1-3-MeCN in the $\mathrm{CO}_{2}$ hydrogenation to formic acid (FA) under buffering conditions ${ }^{\text {a) }}$

$$
\mathrm{CO}_{2}+\mathrm{H}_{2} \stackrel{\text { cat. }[\mathrm{Ru}]}{\longrightarrow} \mathrm{HCOOH}
$$

\begin{tabular}{lllll}
\hline entry & {$[\mathrm{Ru}]$} & $\mathrm{TON}^{\mathrm{b}}$ ) & $\left.\mathrm{TOF} / \mathrm{h}^{-1 \mathrm{c}}\right)$ & $\left.[\mathrm{FA}] / \mathrm{M}^{\mathrm{b}}\right)$ \\
\hline $\mathbf{1}$ & $\mathbf{1}$ & $4520 \pm 40$ & $117 \pm 2.2$ & $1.14 \pm 0.01$ \\
2 & $\mathbf{2}$ & $2190 \pm 40$ & $55 \pm 3.6$ & $0.55 \pm 0.01$ \\
3 & $\mathbf{3}$ & $1930 \pm 40$ & $78 \pm 2.2$ & $0.49 \pm 0.01$ \\
4 & $\mathbf{2 - M e C N}$ & $1950 \pm 40$ & $122 \pm 2.3$ & $0.49 \pm 0.01$ \\
5 & $3-M e C N$ & $1520 \pm 40$ & $50 \pm 0.4$ & $0.39 \pm 0.01$
\end{tabular}

a) Reaction condtions: $6 \mathrm{~mL} \mathrm{DMSO}$ :water (5 v/v\% water), $0.55 \mathrm{M} \mathrm{BMMI.OAc,} 0.25 \mathrm{mM}[R u]$ at $70^{\circ} \mathrm{C}$, $P_{\mathrm{H} 2}=P_{\mathrm{CO} 2}=30$ bar; $\left.{ }^{b}\right)$ determined by ${ }^{1} \mathrm{H}$ NMR spectroscopy after $72 \mathrm{~h}$ using BMMI.OAc as an internal standard, average of two independent runs; c) calculated by linear regression (see $\mathrm{SI}$ ). 
All complexes except 1 displayed a notable, non-productive induction time (see SI, Table S4). High pressure NMR experiments conducted under hydrogen pressure suggest an initial loss of the p-cymene ligand, followed by the formation of hydridic species (Fig. S17, S18) suggesting a complex catalyst activation mechanism that is not dependent solely on the loss or replacement of the ancillary $\mathrm{Cl} / \mathrm{NCMe}$ ligand. No ligand dissociation was observed, indicating that the PYA-Ru entity keeps its integrity during the catalytic reaction. Indeed, variation of the ligand scaffold had a pronounced impact on the catalytic activity of the ruthenium complexes. Complex 1 displays a significantly higher catalyst stability than complexes 2, 3, 2-MeCN according to the pertinent TON values, while 3-MeCN produced the least stable system. The 4520 TONs achieved with complex 1 (Table 1, entry 1) are amongst the highest catalyst performance in the absences of strong bases conditions reported thus far, and the final FA concentration of $1.14 \mathrm{M}$ is very close to the predicted thermodynamic limit of FA concentration of 1.2 M under the conditions assayed.[38, 39, 45] Interestingly, in this work the TOF values are similar to those observed in recent publications for a similar catalytic system, employing $\mathrm{Ru}_{3}(\mathrm{CO})_{12}$ as catalyst.[45] However, the values of TON are lower, suggesting a lower stability of the complex under the conditions assayed. In contrast, complexes 2 and 3 achieved much lower FA concentrations around $0.5 \mathrm{M}$ (entries 2-5), suggesting that these complexes have intrinsic catalytic instability. While complex $\mathbf{1}$ is not the only cationic complex in this series, we note that this complex features a formally neutral pyridylidene-PYA ligand scaffold, whereas the other four complexes evaluated here contain a formally anionic phenyl-PYA ligand.

Complexes 1 and 2-MeCN reach an appreciable maximum turnover frequency (TOF ${ }_{\max }$ ) around $120 \mathrm{~h}^{-1}$ (entries 1,4). Interestingly, complex 2 achieved a significantly lower TOF value $\left(\mathrm{TOF}_{\max }=55 \mathrm{~h}^{-1}\right)$ than 2-MeCN despite the same ligand scaffold. These complexes only differ in their ancillary ligand ( $\mathrm{Cl}$ vs. MeCN). An inverse effect was observed for complexes $\mathbf{3}$ and 3MeCN (entries 3,5). Modification of the PYA unit from a para substituted system in 2 to the 
more electron-donating meta analogue (complex 3) increases the rate from $55 \mathrm{~h}^{-1}$ to $78 \mathrm{~h}^{-1}$, suggesting that electron donating effects are relevant for imparting higher catalytic activity.

These results clearly indicate that both the PYA-ligand and the ancillary ligand play an important role on the catalytic activity. In order to identify the effects determining the rate of catalytic conversion and stability, we investigated a series of parameters such as turnover limiting steps, effect of pressure, and activation energies for this buffered $\mathrm{CO}_{2}$ hydrogenation process.

\section{Analysis of turnover-limiting steps}

In a first approximation, hydrogenation of $\mathrm{CO}_{2}$ to $\mathrm{FA}$ can be divided into two steps. First $\mathrm{CO}_{2}$ inserts into a metal hydride bond to yield a metal formate complex. In the second step $\mathrm{H}_{2}$ reacts with this complex to release FA and regenerate the active hydride (Figure $1 \mathrm{~A}$ ). From this simplified mechanism four scenarios can arise: (i) either $\mathrm{H}_{2}$ activation is the turnover limiting step (TLS) and the rate is solely dependent on the partial pressure of $\mathrm{H}_{2}$, or (ii) $\mathrm{CO}_{2}$ insertion is turnover limiting and thus the rate is dependent only on the partial $\mathrm{CO}_{2}$ pressure, or (iii) both steps display similar rates and a dependence on both $\mathrm{CO}_{2}$ and $\mathrm{H}_{2}$ pressure is observed, or finally (iv) the TLS is outside the simplified mechanism, e.g. ligand dissociation from the pre-catalyst, which will result in no dependence on $\mathrm{CO}_{2}$ nor on $\mathrm{H}_{2}$ pressure. In order to probe the nature of the TLS, we therefore evaluated complexes 1, 2, and $\mathbf{3}$ under varying partial pressures of $\mathrm{CO}_{2}$ and $\mathrm{H}_{2}$. 


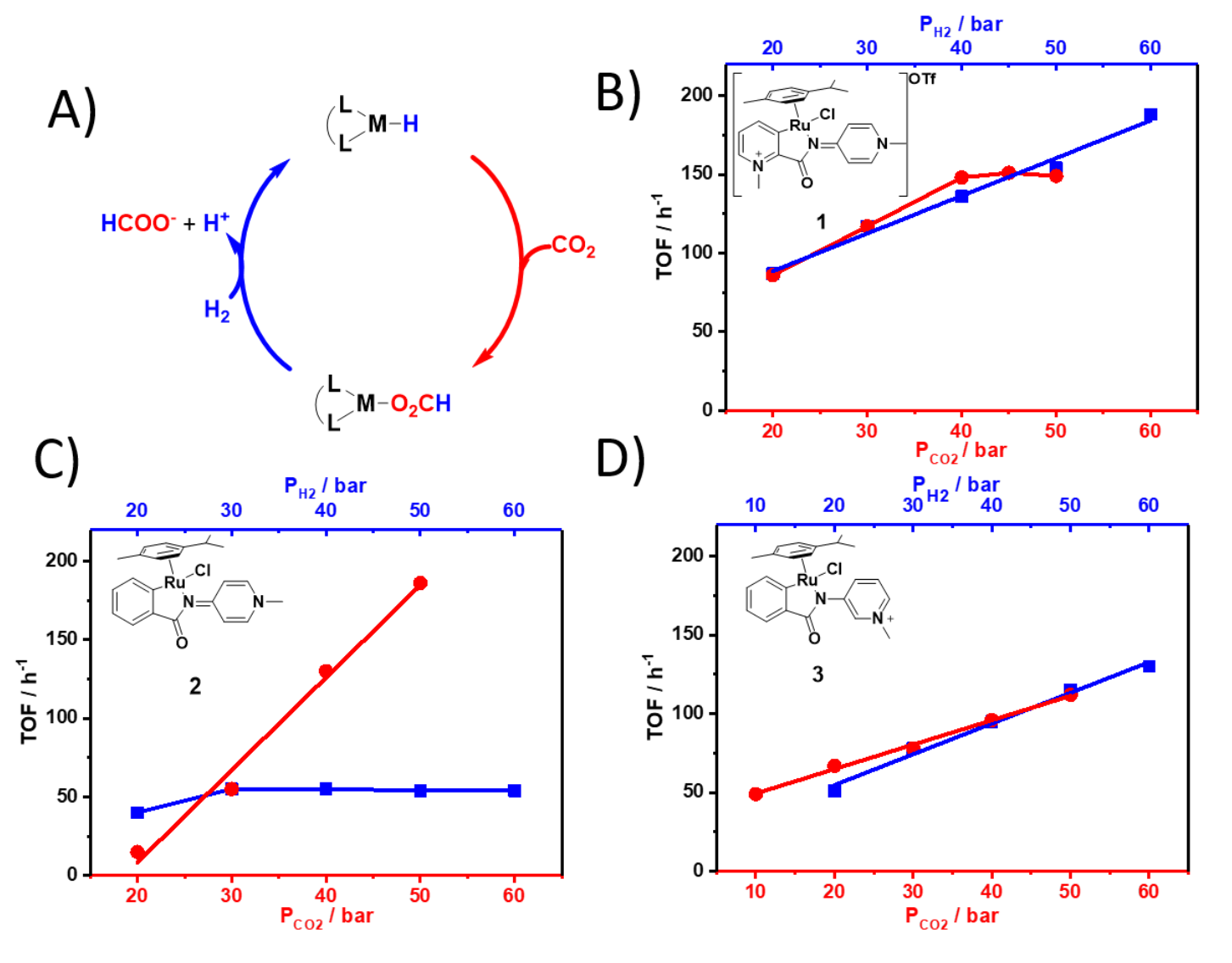

Figure 1 Determination of the turnover limiting step (TLS) for complexes 1, 2 and 3. A) Schematic representation of a simplified mechanism of the hydrogenation of $\mathrm{CO}_{2}$ to $\mathrm{FA}$, divided into two main steps, the insertion of $\mathrm{CO}_{2}$ (red) and $\mathrm{H}_{2}$ activation (blue). B)-D) catalytic activity of complexes 1-3 upon variation of the partial pressure $P_{i}$ of either $\mathrm{CO}_{2}$ (red) or $\mathrm{H}_{2}$ (blue), whilst keeping the pressure of the other reactant constant at 30 bar. Reaction conditions: $T=70^{\circ} \mathrm{C}, 6 \mathrm{~mL} \mathrm{DMSO}: \mathrm{H}_{2} \mathrm{O}\left(5 \mathrm{v} / \mathrm{v} \% \mathrm{H}_{2} \mathrm{O}\right), 0.55$ M BMMI.OAc. and $0.25 \mathrm{mM}$ of ruthenium complex.

The catalytic activity with complex 1 (Figure 1B) is linearly dependent on the partial hydrogen pressure, whilst an increase in partial $\mathrm{CO}_{2}$ pressure led to a plateau around $150 \mathrm{~h}^{-1}$ when reaching 40 bar $\mathrm{CO}_{2}$ pressure. The $\mathrm{CO}_{2}$ dependence of the rate at low partial pressure of $\mathrm{CO}_{2}$ has been attributed to the high solubility of $\mathrm{H}_{2}$ in $\mathrm{CO}_{2}$, which increases the effective concentration of $\mathrm{H}_{2}$ in the reaction media as the pressure of $\mathrm{CO}_{2}$ increases.[61, 62] These results suggest that the TLS is associated with the $\mathrm{H}_{2}$ activation process. A markedly different behavior was observed for complex 2, where the rate is essentially independent of the $\mathrm{H}_{2}$ pressure, yet directly correlates with changes in the partial $\mathrm{CO}_{2}$ pressure (Figure $1 \mathrm{C}$ ), identifying $\mathrm{CO}_{2}$ insertion as the TLS. The pressure-dependence of the catalytic activity of 
complex 2 is about three times stronger than that of complex 1 ( $\Delta$ TOF ca. $5.9 \mathrm{~h}^{-1} \pm 0.5 \mathrm{~h}^{-1}$ per bar $\mathrm{CO}_{2}$ for 2 vs $2.4 \mathrm{~h}^{-1} \pm 0.2 \mathrm{~h}^{-1}$ per bar $\mathrm{H}_{2}$ for 1).[63]

Complex 3 showed a more complex behavior, with a linear dependence on both $\mathrm{H}_{2}$ and $\mathrm{CO}_{2}$ insertion (Figure 1D), suggesting that both steps are energetically closely related. Such a model is supported by catalytic runs for which the total pressure was kept constant at 60 bar, yet the partial pressures were varied (Figure 2). The rate is only moderately affected in this regime. The weakly positive dependence on $\mathrm{H}_{2}$ pressure points to $\mathrm{H}_{2}$ activation as the slightly more energetic and hence turnover-limiting step rather than $\mathrm{CO}_{2}$ insertion.

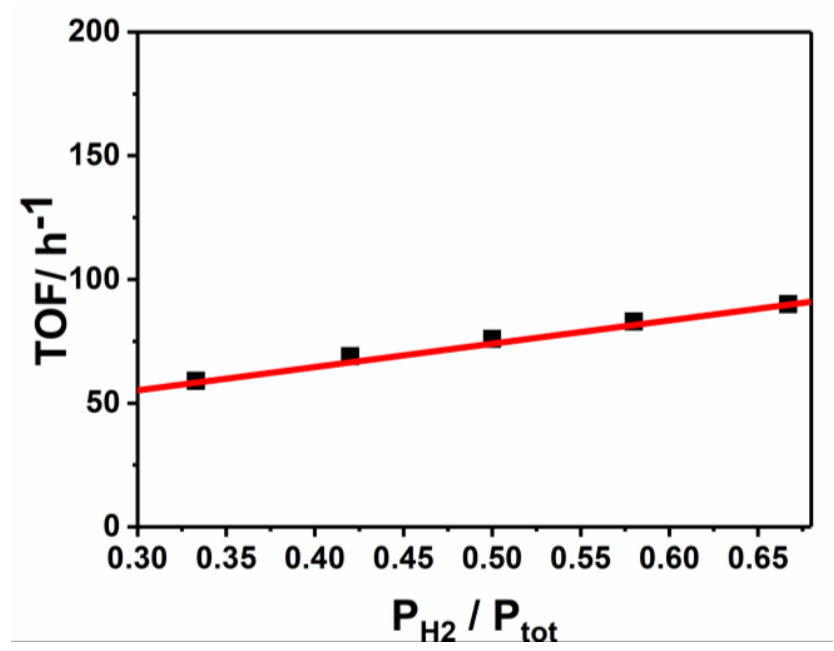

Figure 2. Effect of gas composition on TOF for complex 3 at a constant total pressure (60 bar) with 0.25 $\mathrm{mM}$ of complex 3 and $0.55 \mathrm{M} \mathrm{BMMI.OAc}$ at $70^{\circ} \mathrm{C}$ in $6 \mathrm{~mL} \mathrm{DMSO}: \mathrm{H}_{2} \mathrm{O}\left(5 \mathrm{v} / \mathrm{v} \% \mathrm{H}_{2} \mathrm{O}\right)$.

Interestingly, a change in the TLS as observed for complexes 1 and $\mathbf{2}$ has not been reported for $\mathrm{Ru}(\mathrm{II})$ complexes, even though computational studies have predicted that the activation for $\mathrm{CO}_{2}$ and $\mathrm{H}_{2}$ are energetically close for $\mathrm{Ru}(\mathrm{II})$-catalysts.[64] Calculations on the thermodynamics of the hydrogenation process do not identify any one step to be particularly facile, and therefore the insertion of $\mathrm{CO}_{2}$ may be endergonic or exergonic.[65, 66] However, a change in TLS has been reported upon changing the active metal center. With complexes of $\mathrm{Co}$ and Ir, $\mathrm{CO}_{2}$ insertion is rate limiting whilst for $\mathrm{Ru}$ and Fe the $\mathrm{H}_{2}$ activation is generally considered as the limiting step. [41, 42, 64, 67] 
Table 2 Optimized catalytic performance of complexes 1-3 in terms of TON, TOF and concentration of $F A$. a)

\begin{tabular}{llllll}
\hline Entry & {$[\mathrm{Ru}]$} & $\mathrm{P}_{\mathrm{H} 2}: \mathrm{P}_{\mathrm{CO} 2} /$ bar & $\mathrm{TON}^{\mathrm{b})}$ & $\mathrm{TOF}_{\max } / \mathrm{h}^{-1 \mathrm{c})}$ & {$[\mathrm{FA}] / \mathrm{M}^{\mathrm{b})}$} \\
\hline $\mathbf{1}$ & $\mathbf{1}$ & $60: 30$ & $4520 \pm 40$ & $192 \pm 4$ & $1.15 \pm 0.01$ \\
$\mathbf{3}$ & $\mathbf{2}$ & $30: 50$ & $2010 \pm 40$ & $180 \pm 20$ & $0.51 \pm 0.01$ \\
4 & $\mathbf{3}$ & $60: 30$ & $1930 \pm 40$ & $136 \pm 4$ & $0.49 \pm 0.01$ \\
5 & $\mathbf{3}$ & $30: 50$ & $1930 \pm 40$ & $120 \pm 9$ & $0.49 \pm 0.01$ \\
& $\mathbf{2 - M e C N}$ & $30: 50$ & $1950 \pm 40$ & $340 \pm 60$ & $0.49 \pm 0.01$
\end{tabular}

a) Reaction conditions: $6 \mathrm{~mL}$ DMSO:water (5 v/v\% water) $0.25 \mathrm{mM}$ [Ru], $0.55 \mathrm{M} \mathrm{BMMI.OAc} \mathrm{at} 70^{\circ} \mathrm{C}$; b) determined by ${ }^{1} \mathrm{H}$ NMR spectroscopy after $72 \mathrm{~h}$ using BMMI.OAC as an internal standard, average of two runs; ${ }^{c)}$ Determined as maximum TOF by linear regression of the variation of FA concentration as a function of time.

Identification of the TLS for each complex allows for tailoring the reaction conditions to enhance the catalytic performance of each complex. Under optimized conditions, i.e. in the presence of an excess of the turnover-limiting component, significantly higher TOF $_{\max }$ up to $340 \pm 60 \mathrm{~h}^{-1}$ are accessible (Table 2), even though the TON does not significantly change compared to the original conditions studied (cf Table 1). This observation indicates that the catalytically active species remain unchanged, even though considerably differing reaction conditions are applied.

The variable catalytic activity and the distinct turnover-limiting steps provide evidence that the nature of the ligand plays a significant role in the hydrogenation of $\mathrm{CO}_{2}$ to $\mathrm{FA}$. Even relatively small modifications in the PYA ligand architecture lead to significant changes in the TLS. For example, with 1 containing a chelating pyridylidene unit with the PYA donor, the TLS is associated with $\mathrm{H}_{2}$ activation, whilst substitution of this formally neutral carbene with an anionic phenyl chelating group as in complexes 2 and 2-MeCN switches the TLS to $\mathrm{CO}_{2}$ insertion. With 3, both these steps are energetically close. Furthermore, the differences of complexes 2 and $\mathbf{3}$ indicate that the TLS is partially defined by the electron density at the metal center, as the meta-PYA unit induces a higher electron density at the metal center compared to the paraPYA analogue (see CVs Figure S7 in SI). 
Modulation of the ancillary ligand in complex 2 from $\mathrm{Cl}^{-}$to $\mathrm{MeCN}$ led to a more marked dependence of the catalytic activity on the pressure of $\mathrm{CO}_{2}$ (Figure 3, $\left(\Delta\right.$ TOF ca. $9.0 \mathrm{~h}^{-1}$ per bar $\mathrm{CO}_{2}$ ). The stronger dependence is relevant because the TLS for both complexes is the insertion of $\mathrm{CO}_{2}$.[68] An increase of the partial $\mathrm{CO}_{2}$ pressure up to 50 bar therefore leads to an outstanding $\mathrm{TOF}_{\max }=340 \mathrm{~h}^{-1}$ for complex 2-MeCN. This complex is therefore the most active one of the series investigated here, and also one of the best reported to date for the hydrogenation of $\mathrm{CO}_{2}$ to $\mathrm{FA}$ in the absence of strong bases. Higher rates are only observed under significantly higher pressures[38] or temperatures, and only at very early stages, i.e. at very low concentrations of FA.[69]
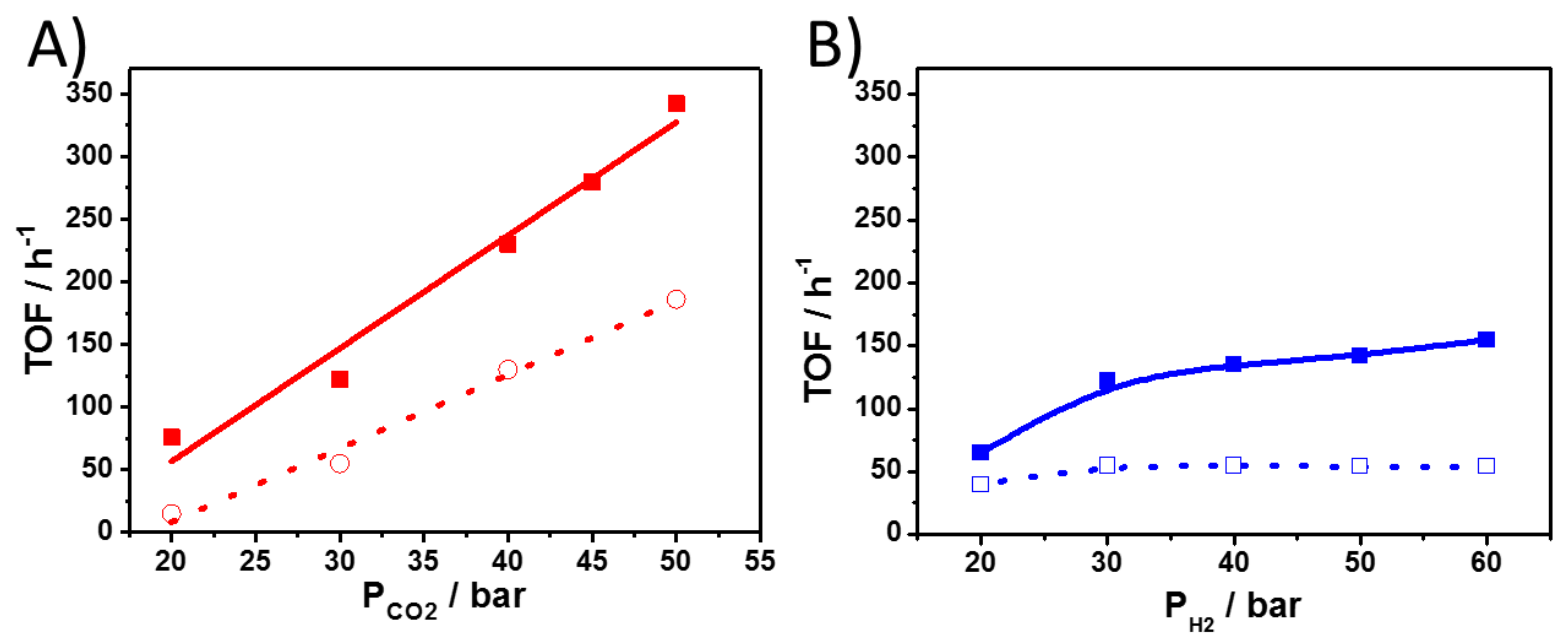

Figure 3. Comparison of catalytic activity of 2 (dotted) and 2-MeCN (solid) upon A) variation of partial $\mathrm{CO}_{2}$ pressures (red) $\left(P\left(\mathrm{H}_{2}\right)=30 \mathrm{bar}\right)$; and $\left.\mathrm{B}\right)$ upon variation of the partial $\mathrm{H}_{2}$ pressures (blue) $\left(P\left(\mathrm{CO}_{2}\right)\right.$ = 30 bar); General conditions: $0.25 \mathrm{mM}[R u], 6 \mathrm{~mL} \mathrm{DMSO}: \mathrm{H}_{2} \mathrm{O}\left(5 \mathrm{v} / \mathrm{v} \% \mathrm{H}_{2} \mathrm{O}\right), 0.55 \mathrm{M} \mathrm{BMMI.OAc}, 70^{\circ} \mathrm{C}$.

Complex 2-MeCN showed only small rate increases from $122 \mathrm{~h}^{-1}$ to $150 \mathrm{~h}^{-1}$ when the partial $\mathrm{H}_{2}$ pressure was increased from 30 to 60 bar (Figure 3B), while complex 2 is completely insensitive to higher $\mathrm{H}_{2}$ pressure (cf Figure $1 \mathrm{C}$ ). These results suggest a different mechanism for these two complexes. The increasing rate at higher $\mathrm{H}_{2}$ pressures with 2-MeCN may be due to an increased concentration of reactant, favorable formation of the active hydride or alternatively a consequence of the higher overall physical pressure. In order to distinguish these effects, complexes 2 and 2-MeCN were investigated at higher pressure entailed by $\mathrm{Ar}$ as an inert gas. The employment of an inert gas enables to decouple the kinetic effects of 
pressure modulation (volume of activation for TLS) from the concentration of reagents that may be part of the rate equation, which will be relevant to distinguish between and inner and an outer sphere mechanism.[70, 71]

Table 3 Effect of pressure on catalytic performance of 2 and $2-M e C N$ a)

\begin{tabular}{|c|c|c|c|c|c|c|c|}
\hline Entry & Complex & $\mathbf{T} /{ }^{\circ} \mathbf{C}$ & Ar / bar & {$[\mathrm{FA}] / \mathrm{M}$} & TON & TOF $/ \mathbf{h}^{-1}$ & $\Delta \mathbf{V}^{\ddagger} / \mathbf{M}^{-1}$ b) \\
\hline 1 & 2 & 90 & 50 & $0.180 \pm 0.01$ & $695 \pm 38$ & $34.5 \pm 1.7$ & $\geq 0$ \\
\hline 2 & 2 & 90 & - & $0.197 \pm 0.005$ & $749 \pm 38$ & $37.5 \pm 2.5$ & - \\
\hline 3 & 2-MeCN & 80 & 50 & $0.177 \pm 0.005$ & $695 \pm 16$ & $37.5 \pm 0.6$ & $<0$ \\
\hline 4 & 2-MeCN & 80 & - & $0.143 \pm 0.005$ & $564 \pm 22$ & $31 \pm 1.2$ & - \\
\hline \multicolumn{8}{|c|}{$\begin{array}{l}\text { a) Reaction conditions: } P_{\mathrm{CO} 2}=20 \text { bar, } P_{\mathrm{H} 2}=10 \text { bar, } 6 \mathrm{~mL} \text { DMSO:water (5 v/v\% water), } 0.55 \mathrm{M} \\
\text { BMMI.OAc, } 0.25 \mathrm{mM}[R u], 20 \mathrm{~h} \text {, average of } 3 \text { runs; b) sign of } \Delta \mathrm{V}^{\ddagger} \text { estimated from TOF difference } \\
\text { between catalytic runs with and without Ar. Error calculation was undertaken according to standard } \\
\text { statistical procedures (see SI section 2.5.1) }\end{array}$} \\
\hline
\end{tabular}

The addition of 50 bar of argon to the catalytic system based on complex 2 did not lead to any significant change in rate of catalytic $\mathrm{CO}_{2}$ hydrogenation (Table 3 , entry 1 vs 2 ). It can be observed that the differences observed are within the margin of error based on the standard deviation of 3 replicates, thus reinforcing the hypothesis that pressure of the system is not playing a significant role on the catalytic performance observed. In contrast, a $20 \%$ increase of the TOF was observed when 2-MeCN was used as the catalyst precursor (entry 3 vs 4). The increased rate noted for $\mathbf{2}-\mathrm{MeCN}$ indicates a negative volume of activation $\Delta \mathrm{V}^{\ddagger}$ according to Eq. 1 in the SI. A statistical significance analysis was undertaken to confirm that the difference in TON and TOF observed were significant (see SI, section 2.5, table S13). The results confirmed that the variations in TON and TOF were significant for complex 2-MeCN but not for 2.

This negative value of $\Delta \mathrm{V}^{\ddagger}$ suggests an associative process for 2-MeCN in the TLS, while the TLS for the hydrogenation with complex 2 is volume-neutral. Two predominant mechanisms 
for the $\mathrm{CO}_{2}$ insertion have been discussed which depend on the nucleophilicity and sterics around the metal center. Hence, strong nucleophiles such as metal amines, and metal hydrides with low steric demand generally proceed through a so-called inner sphere mechanism, involving coordination of $\mathrm{CO}_{2}$ to the metal center and simultaneous hydride transfer to the $\mathrm{CO}_{2}$ in a concerted, associative fashion.[71, 72] With most metal hydrides and other weaker nucleophiles, an outer sphere mechanism is prevalent, consisting of an initial hydride transfer to $\mathrm{CO}_{2}$ and formation of a zwitterionic intermediate comprised of a positively charged metal center and a formate anion. In a second step this zwitterionic intermediate rearranges to the formate complex (cf. Figure 1A).[71, 72] According to this model, the negative volume of activation implies a concerted associative TLS for the 2-MeCN-catalyzed process, whilst with $\mathbf{2}$ the outer sphere mechanism with no significant volume change is dominant. Moreover, these data suggest that the ruthenium-hydride intermediate derived from 2-MeCN has a lower steric demand or is a stronger nucleophile than the one derived from 2. It has been shown that the inner sphere mechanism proceeds faster than the outer sphere mechanism,[71] in agreement with the twice higher rate of $\mathrm{CO}_{2}$ hydrogenation observed with 2-MeCN compared to 2 (340 vs $186 \mathrm{~h}^{-1}$, cf Table 2).

\section{Ligand electronic effects on catalytic activity}

The catalytic implications of varying electronic effects of the different PYA ligand scaffolds in complexes 1-3 has been quantified by determining the activation energy for $\mathrm{CO}_{2}$ hydrogenation with each complex. Redox potentials of the parent complexes 1-3 were used as a proxy for the electron density at the metal centre. Both the activation energy and the redox potential were compared to each other (Table 4).

An Arrhenius plot from rate measurements in the $60-90^{\circ} \mathrm{C}$ temperature range is linear (Figure 4) and provides the activation energies $\left(E_{a}\right)$ and pre-exponential factors (In A) for the complexes (Table 4). To further probe the electronic flexibility of the PYA ligand, the activation energy for complex 2 was also determined in THF as a less polar solvent than DMSO. Lower polarity solvents were previously shown to favour the neutral PYA resonance structure more 
than the zwitterionic one (cf. Scheme 1), resulting in a lower electron density at the metal centre ${ }^{52-54}$ Activation energies in THF as the main solvent were measured in the presence of 1-decyl-2,3-dimethylimidazolium acetate $\left(\mathrm{C}_{10} \mathrm{MMI}\right.$.OAc) rather than BMMI.OAc as IL media.

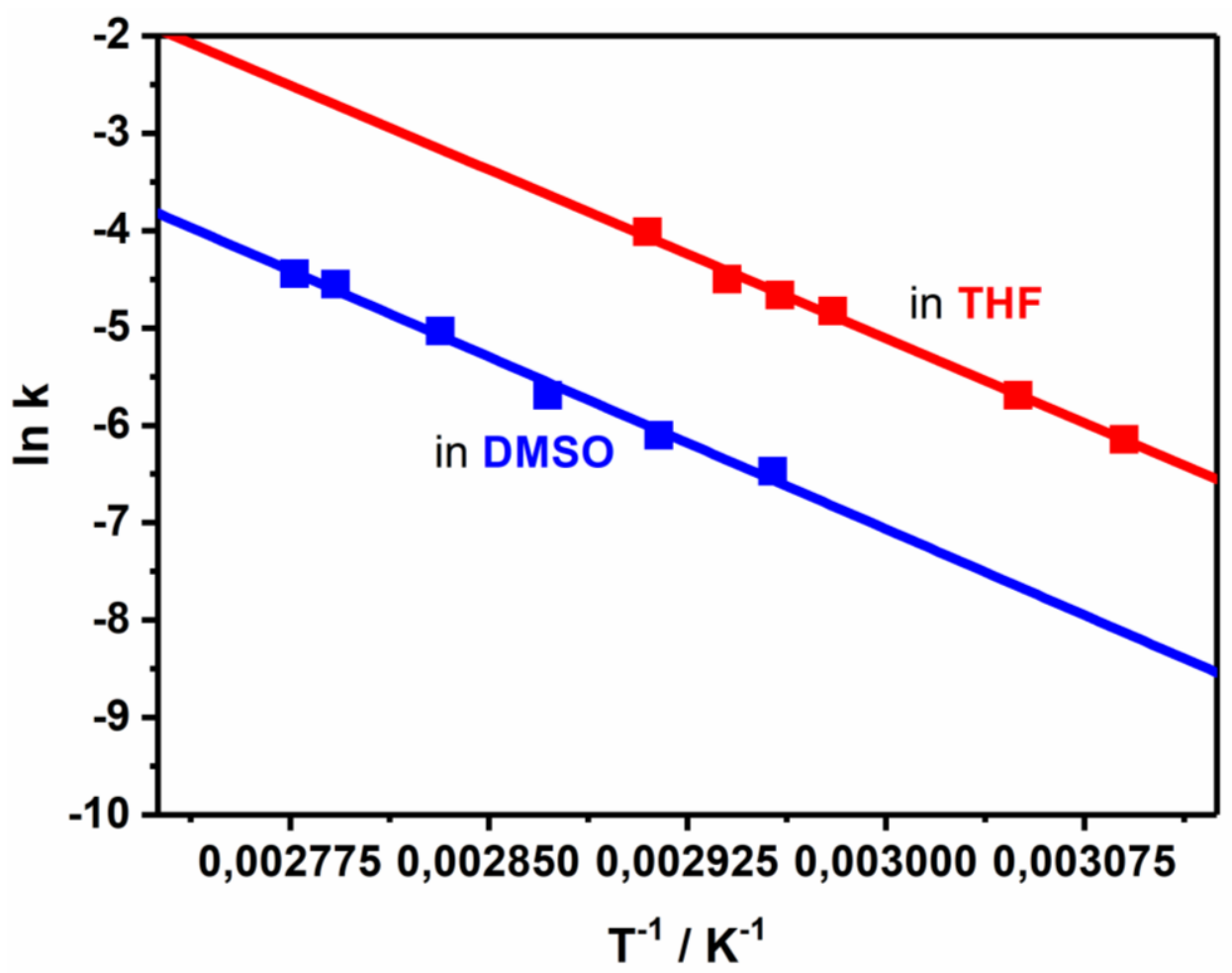

Figure 4. Arrhenius plot of 2 in DMSO:water with 0.55 M BMMI.OAC (blue), and in THF:water with 0.55 M C10MMI.OAC (red) using $1.3 \mathrm{mM}$ catalyst and $P_{\mathrm{CO} 2}=P_{\mathrm{H} 2}=20$ bar

Complex 2 in polar and apolar media and complex $\mathbf{3}$ seem to follow a correlation in between the activation energy and the energy donation ability of the ligands, which has been described previously in literature.[80] Here, the redox potentials for complexes 1-3 have been experimentally determined to be employed as proxies for the electron density transfer ability to the metal centre. When compared to the para-PYA ligand system in complex $2\left(\Delta \mathrm{E}_{\mathrm{a}}=86\right.$ $\mathrm{kJ} \mathrm{mol}^{-1}$; Table 4, entry 2), the meta-PYA ligand of complex $\mathbf{3}$ is stronger donating, which is also shown by the $60 \mathrm{mV}$ easier $\mathrm{Ru}{ }^{1 / / I I}$ oxidation, compare table 4 entry 2 and 3.[73] This increased electron density lowers the activation energy by $15 \mathrm{~kJ} \mathrm{~mol}^{-1}$ (entry 3 ). While the turnover limiting step for complex 2 is the $\mathrm{CO}_{2}$ insertion, it is difficult to assign the turnover limiting step for complex 3 (see figure 1D). This effect may be rationalised by an increasing 
hydricity of the hydride with more-electron-rich metal centres, which facilitates $\mathrm{CO}_{2}$ insertion and enhances the energetic barrier for the regeneration of the hydride intermediate.

In contrast, the larger contribution of the neutral resonance structure of the para-PYA ligand in THF lowers the electron density at ruthenium, which also imparts a $10 \mathrm{~kJ} \mathrm{~mol}^{-1}$ higher activation energy compared to the same complex in more polar DMSO solvent (entry 4). This observation suggests a relationship between the hydricity of the critical ruthenium hydride intermediate and the catalytic activity, as established previously for a wide range of catalysts .$[30,32-34,65,74-79]$ The hydricity has been shown to directly correlate with the electron density at the metal centre, hence allowing to estimate the hydride transfer capability of metal complexes and to compare it to the hydride donor-ability of formate/formic acid. In general, higher hydride transfer capabilities lead to higher catalytic activities in the hydrogenation of $\mathrm{CO}_{2}$. A relationship between the oxidation potential and the catalytic activity has been established previously with other Ru-catalysts in the hydrogenation of $\mathrm{CO}_{2}$ under basic conditions.[80, 81]

Table 4 Comparison of the redox potential and Arrhenius activation parameters for the different PYA derived catalysts. ${ }^{\text {a) }}$

\begin{tabular}{|c|c|c|c|c|c|c|c|}
\hline Entry & Complex & Solvent & Ionic liquid & TLS $^{\text {b) }}$ & $\begin{array}{c}\Delta \mathrm{E}_{\mathrm{a}} / \\
\mathrm{kJ} \mathrm{mol}^{-1}\end{array}$ & $\operatorname{In} A$ & $E_{1 / 2} / V$ \\
\hline 1 & 1 & DMSO:water & BMMI.OAc & 1 & $62 \pm 4.2$ & $18 \pm 1.5$ & $0.45^{b)}$ \\
\hline 2 & 2 & DMSO:water & BMMI.OAc & 2 & $86 \pm 5.1$ & $24 \pm 1.8$ & $0.17^{b)}$ \\
\hline 3 & 3 & DMSO:water & BMMI.OAc & $1 / 2$ & $71 \pm 4.5$ & $19 \pm 1.6$ & $0.11^{b)}$ \\
\hline 4 & 2 & THF:water & $\mathrm{C}_{10} \mathrm{MMI} . \mathrm{OAc}$ & 2 & $96 \pm 3.1$ & $30 \pm 1.1$ & 0.35 \\
\hline
\end{tabular}

a) Reaction conditions: $6 \mathrm{~mL}$ solvent with $5 \mathrm{v} / \mathrm{v} \% \mathrm{H}_{2} \mathrm{O}, 0.55 \mathrm{M} \mathrm{IL}$ and $P\left(\mathrm{H}_{2}\right)=P\left(\mathrm{CO}_{2}\right)=20$ bar and 1.3 $\mathrm{mM}$ catalyst concentration. ${ }^{b}$ redox potentials in $\mathrm{MeNO}_{2}$, (see ref 71); all potentials vs Fc ${ }^{+} / \mathrm{Fc}$. Errors determined calculating the standard deviation from the Arrhenius plots. c) TLS mechanistic steps: 1) $\mathrm{H}_{2}$ activation; 2) $\mathrm{CO}_{2}$ activation. 
While the activation energies of complex 2 and $\mathbf{3}$ correlate with the metal redox properties, complex 1 shows a distinct behaviour and features the lowest activation energy $\left(\Delta \mathrm{E}_{\mathrm{a}}=62 \mathrm{~kJ}\right.$ $\mathrm{mol}^{-1}$ ) despite having the lowest electron density at ruthenium according to cyclic voltammetry (entry 1), suggesting a distinct mechanistic difference in between complex $\mathbf{1}$ and $\mathbf{2}$, respectively 3. Furthermore, complex 1 generated a much higher concentration of FA, and TONs were much higher than those of complexes 2 and 3 (Figure 5B). Indeed, complex 1 achieved the equilibrium concentrations, extracted from our previous report,[45] while complexes $\mathbf{2}$ and $\mathbf{3}$ achieved a fixed and lower concentration under all temperatures assayed. These data indicate fundamental differences in the active species derived from 1 compared to those of $\mathbf{2}$ and $\mathbf{3}$, suggesting a distinct reaction mechanism for complex $\mathbf{1}$. This difference has been attributed to a beneficial effect of the overall neutral carbene donor ligand pyridylidene-PYA donor ligand in complex 1, which imparts higher robustness of the catalytically active species than the anionic phenyl-PYA chelates in complexes 2 and $\mathbf{3}$. Moreover, this neutral ligand entails less electron density at the ruthenium centre of complex $\mathbf{1}$ compared to that of $\mathbf{2}$ and $\mathbf{3}$ (Figure 5B), which implies a less nucleophilic metal hydride for the catalysts derived from 1 (Figure 5A). Larger quantities of FA product results in more acidic conditions, which protonate the metal-hydride to catalytically inactive metal-dihydrogen species. Hence, the higher resistance to acidification of the hydride originating from complex 1 results in higher TON and FA concentrations compared to the performance of complexes 2 and 3 (Figure 5B). Irrespective of the exact deactivation mechanism for those complexes, the results obtained here indicate that complex 1 represent an attractive lead complex to develop new high-turnover catalysts for the hydrogenation of $\mathrm{CO}_{2}$ to $\mathrm{FA}$ under buffering conditions. 
A)

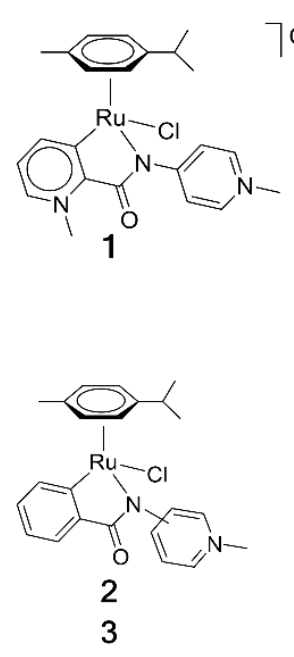

B)
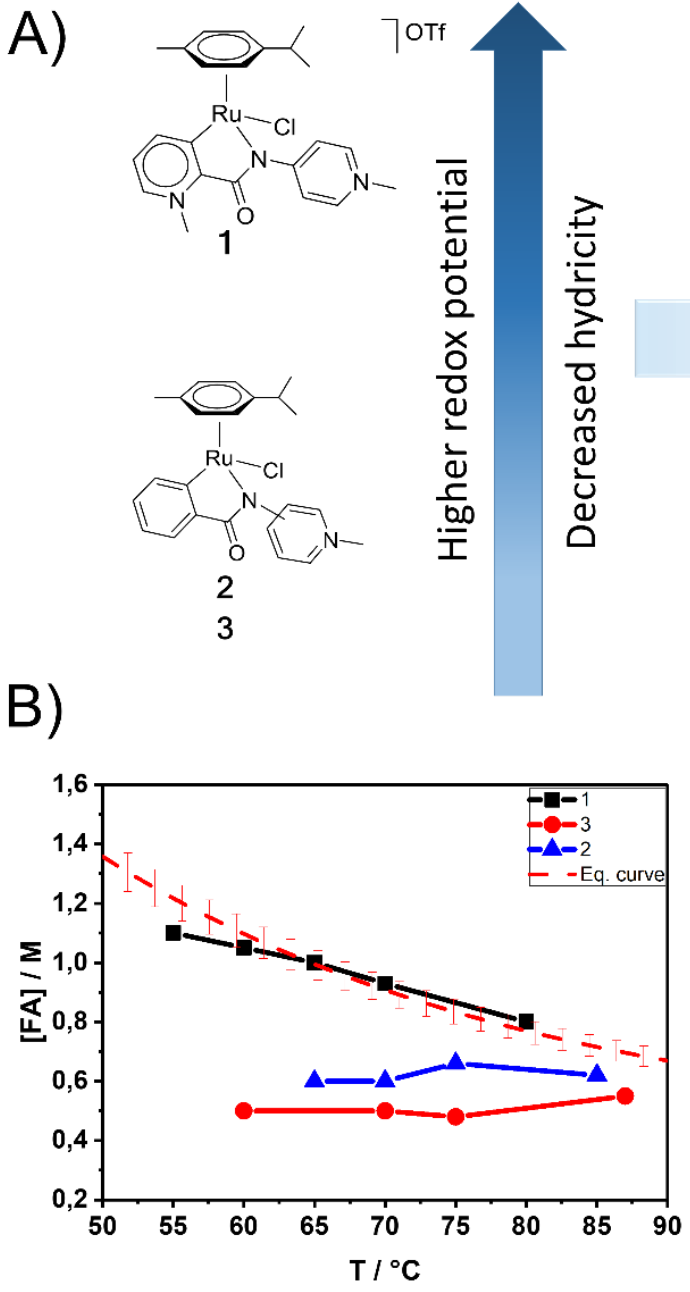

C)

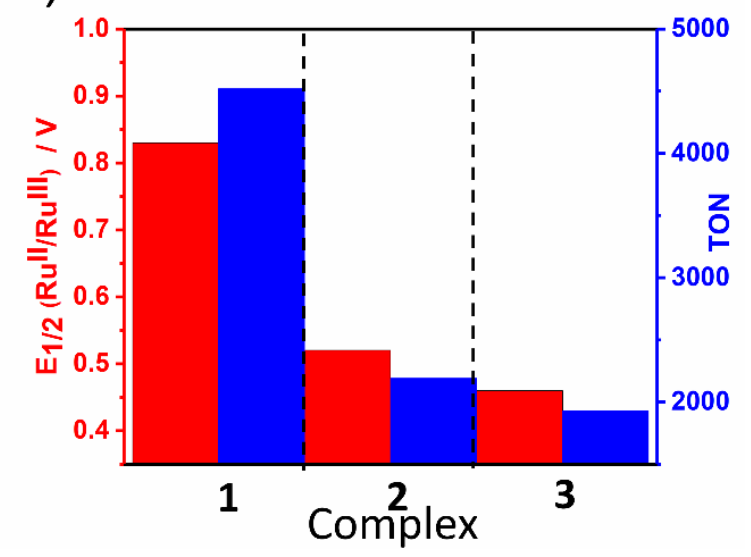

Figure 5. A) Correlation between hydricity and catalyst robustness against acidification of the crucial ruthenium hydride intermediate. B) Concentration profiles of FA as a function of $T$ for complexes 1-3, Reaction conditions: $8 \mu \mathrm{mol}$ catalyst, 0.55M BMMI.OAc, $6 \mathrm{~mL}$ of DMSO:water (5 $\mathrm{v} / \mathrm{v} \%$ water) $P_{C O 2}=$ $P_{\mathrm{H} 2}=20$ bar. Dashed red line represents the equilibrium curve calculated for the same experimental conditions with a related catalytic system. [45] Error bars are 5\%. C) Correlation between redox potentials $E_{1 / 2}(R u(I I) / R u(I I I))$ values of complexes 1-3 in $\mathrm{MeNO}_{2}$ as proxy for DMSO and the catalytic activity observed. The redox potential indicates the electrondonation ability of the ligands to metalin the complexes, which is linked to the resistance towards acidification of the complexes. Experimental conditions in table 1.

\section{Conclusions}

The catalytic hydrogenation of $\mathrm{CO}_{2}$ to form FA in the absence of strong bases has a number of technical advantages and represents a more sustainable approach compared to the established base-assisted procedures. Direct hydrogenation has inherently a very high atom 
economy and therefore represents a sustainable alternative to generate chemicals and fuels from $\mathrm{CO}_{2}$. Specific variation of the ligands bound to the catalytically active ruthenium center provided relevant insights into the mechanism of the reaction and the factors that influence the catalyst performance in terms of TON and TOF. Fine-tuning of the electron density at the metal center is key for catalyst efficiency, with a dual effect observed: high-electron density facilitates $\mathrm{CO}_{2}$ bonding and increases TOF, even though it also enhances the hydricity of the critical ruthenium hydride intermediate, which favours catalyst protonation due to the increasing acidity of the medium due to the formation of FA. Hence, while high electron density at the metal is beneficial for TOF optimization, low electron density favours the hydridedihydrogen equilibrium to the catalytically active hydride side, thus enabling high TON values. This ambivalence of electron density emphasizes the relevance of fine-tuning the electronic configuration of the metal center. Moreover, the type of chelating PYA ligand has a direct influence on the nature of the TLS and depending on the set of ligands, either $\mathrm{H}_{2}$ addition or $\mathrm{CO}_{2}$ insertion have been observed as limiting step. Likewise, the ancillary ligand $\left(\mathrm{Cl}^{-} \mathrm{vs}\right.$ $\mathrm{MeCN}$ ) modulates the mechanism of $\mathrm{CO}_{2}$ insertion from inner to outer sphere.

Most interestingly, the catalyst precursor comprised of a formally neutral pyridylidene-PYA ligand showed unique activity. Specifically, the hydricity is markedly reduced and the catalytically active ruthenium hydride species stabilized, which prevents protonation even in the acidic product solution. As a consequence, these complex features results in high turnover frequency and also a two-fold increase in TON compared to the other complexes, hence representing an attractive lead for further catalyst development.

\section{Acknowledgements}

Dr Christof Jaeger is gratefully acknowledged for insightful discussions. The Faculty of Engineering from the University of Nottingham, the Generalitat Valenciana (CIDEGENT 2018/36), the European Research Council (CoG 615653) and the Swiss National Science Foundation (200020_182663) are gratefully acknowledged for funding. 


\section{References}

[1] J. Klankermayer, S. Wesselbaum, K. Beydoun, W. Leitner, Selective Catalytic Synthesis Using the Combination of Carbon Dioxide and Hydrogen: Catalytic Chess at the Interface of Energy and Chemistry, Angew. Chem. Int. Ed., 55 (2016) 7296-7343.

[2] K. Sordakis, C. Tang, L.K. Vogt, H. Junge, P.J. Dyson, M. Beller, G. Laurenczy, Homogeneous Catalysis for Sustainable Hydrogen Storage in Formic Acid and Alcohols, Chem. Rev., 118 (2018) 372-433.

[3] W. Reutemann, H. Kieczka, Formic Acid, Ullmann's Encyclopedia of Industrial Chemistry, Wiley-VCH Verlag GmbH \& Co. KGaA2000.

[4] N. Mac Dowell, P.S. Fennell, N. Shah, G.C. Maitland, The role of CO2 capture and utilization in mitigating climate change, Nat. Clim. Change, 7 (2017) 243.

[5] J.F. Hull, Y. Himeda, W.-H. Wang, B. Hashiguchi, R. Periana, D.J. Szalda, J.T. Muckerman, E. Fujita, Reversible hydrogen storage using $\mathrm{CO} 2$ and a proton-switchable iridium catalyst in aqueous media under mild temperatures and pressures, Nat. Chem., 4 (2012) 383-388.

[6] B. Loges, A. Boddien, F. Gärtner, H. Junge, M. Beller, Catalytic Generation of Hydrogen from Formic acid and its Derivatives: Useful Hydrogen Storage Materials, Topics Catal., 53 (2010) 902-914.

[7] M. Grasemann, G. Laurenczy, Formic acid as a hydrogen source - recent developments and future trends, Energy Environ. Sci., 5 (2012) 8171-8181.

[8] B. Loges, A. Boddien, H. Junge, M. Beller, Controlled Generation of Hydrogen from Formic Acid Amine Adducts at Room Temperature and Application in $\mathrm{H} 2 / \mathrm{O} 2$ Fuel Cells, Angew. Chem. Int. Ed., 47 (2008) 3962-3965.

[9] T.C. Johnson, D.J. Morris, M. Wills, Hydrogen generation from formic acid and alcohols using homogeneous catalysts, Chem. Soc. Rev., 39 (2010) 81-88.

[10] T. Schaub, R.A. Paciello, A Process for the Synthesis of Formic Acid by $\mathrm{CO} 2$

Hydrogenation: Thermodynamic Aspects and the Role of CO, Angew. Chem. Int. Ed., 50 (2011) 7278-7282.

[11] W. Leitner, Carbon Dioxide as a Raw Material: The Synthesis of Formic Acid and Its Derivatives from CO2, Angew. Chem. Int. Ed. Eng., 34 (1995) 2207-2221.

[12] R. Tanaka, M. Yamashita, K. Nozaki, Catalytic Hydrogenation of Carbon Dioxide Using Ir(III)-Pincer Complexes, J. Am. Chem. Soc., 131 (2009) 14168-14169.

[13] A. Azua, S. Sanz, E. Peris, Water-Soluble IrlII N-Heterocyclic Carbene Based Catalysts for the Reduction of $\mathrm{CO} 2$ to Formate by Transfer Hydrogenation and the Deuteration of Aryl Amines in Water, Chem. Eur. J., 17 (2011) 3963-3967.

[14] S. Sanz, A. Azua, E. Peris, '([small eta]6-arene)Ru(bis-NHC)' complexes for the reduction of $\mathrm{CO} 2$ to formate with hydrogen and by transfer hydrogenation with $\mathrm{iPrOH}$, Dalton Trans., 39 (2010) 6339-6343.

[15] W.-H. Wang, J.F. Hull, J.T. Muckerman, E. Fujita, Y. Himeda, Second-coordinationsphere and electronic effects enhance iridium(iii)-catalyzed homogeneous hydrogenation of carbon dioxide in water near ambient temperature and pressure, Energy Environ. Sci., 5 (2012) 7923-7926.

[16] Y. Himeda, N. Onozawa-Komatsuzaki, H. Sugihara, K. Kasuga, Simultaneous Tuning of Activity and Water Solubility of Complex Catalysts by Acid-Base Equilibrium of Ligands for Conversion of Carbon Dioxide, Organometallics, 26 (2007) 702-712. 
[17] Y. Himeda, S. Miyazawa, T. Hirose, Interconversion between Formic Acid and H2/CO2 using Rhodium and Ruthenium Catalysts for $\mathrm{CO} 2$ Fixation and $\mathrm{H} 2$ Storage, ChemSusChem, 4 (2011) 487-493.

[18] G.A. Filonenko, E.J.M. Hensen, E.A. Pidko, Mechanism of CO2 hydrogenation to formates by homogeneous Ru-PNP pincer catalyst: from a theoretical description to performance optimization, Catalysis Science \& Technology, 4 (2014) 3474-3485.

[19] G.A. Filonenko, D. Smykowski, B.M. Szyja, G. Li, J. Szczygieł, E.J.M. Hensen, E.A. Pidko, Catalytic Hydrogenation of $\mathrm{CO} 2$ to Formates by a Lutidine-Derived Ru-CNC Pincer Complex: Theoretical Insight into the Unrealized Potential, ACS Catal., 5 (2015) 1145-1154.

[20] G.A. Filonenko, R. van Putten, E.N. Schulpen, E.J.M. Hensen, E.A. Pidko, Highly Efficient Reversible Hydrogenation of Carbon Dioxide to Formates Using a Ruthenium PNP-Pincer Catalyst, ChemCatChem, 6 (2014) 1526-1530.

[21] Y. Inoue, H. Izumida, Y. Sasaki, H. Hashimoto, CATALYTIC FIXATION OF CARBON DIOXIDE TO FORMIC ACID BY TRANSITION-METAL COMPLEXES UNDER MILD CONDITIONS, Chem. Lett., 5 (1976) 863-864.

[22] J.C. Tsai, K.M. Nicholas, Rhodium-catalyzed hydrogenation of carbon dioxide to formic acid, J. Am. Chem. Soc., 114 (1992) 5117-5124.

[23] R. Fornika, H. Gorls, B. Seemann, W. Leitner, Complexes [(P2)Rh(hfacac)](P2= bidentate chelating phosphane, hfacac = hexafluoroacetylacetonate) as catalysts for $\mathrm{CO} 2$

hydrogenation: correlations between solid state structures, 103Rh NMR shifts and catalytic activities, J. Chem. Soc. Chem. Commun., (1995) 1479-1481.

[24] E. Graf, W. Leitner, Direct formation of formic acid from carbon dioxide and dihydrogen using the $[\{\mathrm{Rh}(\mathrm{cod}) \mathrm{Cl}\} 2]-\mathrm{Ph} 2 \mathrm{P}(\mathrm{CH} 2) 4 \mathrm{PPh} 2$ catalyst system, J. Chem. Soc. Chem. Commun., (1992) 623-624.

[25] J. Elek, L. Nádasdi, G. Papp, G. Laurenczy, F. Joó, Homogeneous hydrogenation of carbon dioxide and bicarbonate in aqueous solution catalyzed by water-soluble ruthenium(II) phosphine complexes, Appl. Catal. A Gen., 255 (2003) 59-67.

[26] C. Ziebart, C. Federsel, P. Anbarasan, R. Jackstell, W. Baumann, A. Spannenberg, M. Beller, Well-Defined Iron Catalyst for Improved Hydrogenation of Carbon Dioxide and Bicarbonate, J. Am. Chem. Soc., 134 (2012) 20701-20704.

[27] L. Robert, D.P. Yael, L. Gregory, S.L.J. W., B.D. Yehoshoa, M. David, Low-Pressure Hydrogenation of Carbon Dioxide Catalyzed by an Iron Pincer Complex Exhibiting Noble Metal Activity, Angew. Chem. Int. Ed., 50 (2011) 9948-9952.

[28] T. Zell, D. Milstein, Hydrogenation and Dehydrogenation Iron Pincer Catalysts Capable of Metal-Ligand Cooperation by Aromatization/Dearomatization, Acc. Chem. Res., 48 (2015) 1979-1994.

[29] Y. Zhang, A.D. MacIntosh, J.L. Wong, E.A. Bielinski, P.G. Williard, B.Q. Mercado, N. Hazari, W.H. Bernskoetter, Iron catalyzed CO2 hydrogenation to formate enhanced by Lewis acid co-catalysts, Chem. Sci., 6 (2015) 4291-4299.

[30] S.A. Burgess, A.J. Kendall, D.R. Tyler, J.C. Linehan, A.M. Appel, Hydrogenation of CO2 in Water Using a Bis(diphosphine) Ni-H Complex, ACS Catal., 7 (2017) 3089-3096.

[31] S. Chakraborty, J. Zhang, J.A. Krause, H. Guan, An Efficient Nickel Catalyst for the Reduction of Carbon Dioxide with a Borane, J. Am. Chem. Soc., 132 (2010) 8872-8873. [32] S.A. Burgess, A.M. Appel, J.C. Linehan, E.S. Wiedner, Changing the Mechanism for CO2 Hydrogenation Using Solvent-Dependent Thermodynamics, Angew. Chem. Int. Ed., 56 (2017) 15002-15005. 
[33] S.A. Burgess, K. Grubel, A.M. Appel, E.S. Wiedner, J.C. Linehan, Hydrogenation of CO2 at Room Temperature and Low Pressure with a Cobalt Tetraphosphine Catalyst, Inorg. Chem., 56 (2017) 8580-8589.

[34] M.S. Jeletic, E.B. Hulley, M.L. Helm, M.T. Mock, A.M. Appel, E.S. Wiedner, J.C. Linehan, Understanding the Relationship Between Kinetics and Thermodynamics in $\mathrm{CO} 2$

Hydrogenation Catalysis, ACS Catal., 7 (2017) 6008-6017.

[35] Z. Zhang, S. Hu, J. Song, W. Li, G. Yang, B. Han, Hydrogenation of CO2 to Formic Acid Promoted by a Diamine-Functionalized Ionic Liquid, ChemSusChem, 2 (2009) 234-238.

[36] Z. Zhang, Y. Xie, W. Li, S. Hu, J. Song, T. Jiang, B. Han, Hydrogenation of Carbon Dioxide is Promoted by a Task-Specific lonic Liquid, Angew. Chem. Int. Ed., 47 (2008) 1127-1129.

[37] S. Wesselbaum, U. Hintermair, W. Leitner, Continuous-Flow Hydrogenation of Carbon Dioxide to Pure Formic Acid using an Integrated scCO2 Process with Immobilized Catalyst and Base, Angew. Chem., 124 (2012) 8713-8716.

[38] K. Rohmann, J. Kothe, M.W. Haenel, U. Englert, M. Hölscher, W. Leitner, Hydrogenation of $\mathrm{CO} 2$ to Formic Acid with a Highly Active Ruthenium Acriphos Complex in DMSO and DMSO/Water, Angew. Chem. Int. Ed., 55 (2016) 8966-8969.

[39] S. Moret, P.J. Dyson, G. Laurenczy, Direct synthesis of formic acid from carbon dioxide by hydrogenation in acidic media, Nature Commun. 5 (2014) 4017.

[40] A.R. Sahoo, F. Jiang, C. Bruneau, G.V.M. Sharma, S. Suresh, T. Roisnel, V. Dorcet, M. Achard, Phosphine-pyridonate ligands containing octahedral ruthenium complexes: access to esters and formic acid, Catalysis Science \& Technology, 7 (2017) 3492-3498.

[41] H. Hayashi, S. Ogo, S. Fukuzumi, Aqueous hydrogenation of carbon dioxide catalysed by water-soluble ruthenium aqua complexes under acidic conditions, Chem Commun, (2004) 2714-2715.

[42] S. Ogo, R. Kabe, H. Hayashi, R. Harada, S. Fukuzumi, Mechanistic investigation of CO2 hydrogenation by Ru(ii) and Ir(iii) aqua complexes under acidic conditions: two catalytic systems differing in the nature of the rate determining step, Dalton Trans., (2006) 46574663.

[43] G. Zhao, F. Joó, Free formic acid by hydrogenation of carbon dioxide in sodium formate solutions, Catal. Commun., 14 (2011) 74-76.

[44] M.I. Qadir, A. Weilhard, J.A. Fernandes, I. de Pedro, B.J.C. Vieira, J.C. Waerenborgh, J. Dupont, Selective Carbon Dioxide Hydrogenation Driven by Ferromagnetic RuFe Nanoparticles in lonic Liquids, ACS Catal., 8 (2018) 1621-1627.

[45] A. Weilhard, M.I. Qadir, V. Sans, J. Dupont, Selective CO2 Hydrogenation to Formic Acid with Multifunctional Ionic Liquids, ACS Catal., 8 (2018) 1628-1634.

[46] Y. Yasaka, C. Wakai, N. Matubayasi, M. Nakahara, Controlling the Equilibrium of Formic Acid with Hydrogen and Carbon Dioxide Using lonic Liquid, J. Phys. Chem. A, 114 (2010) 3510-3515.

[47] M.E. Doster, S.A. Johnson, Selective C?]F Bond Activation of Tetrafluorobenzenes by Nickel(0) with a Nitrogen Donor Analogous to N-Heterocyclic Carbenes, Angew. Chem. Int. Ed., 48 (2009) 2185-2187.

[48] Q. Shi, R.J. Thatcher, J. Slattery, P.S. Sauari, A.C. Whitwood, P.C. McGowan, R.E. Douthwaite, Synthesis, Coordination Chemistry and Bonding of Strong N-Donor Ligands Incorporating the 1H-Pyridin-(2E)-Ylidene (PYE) Motif, Chem. Eur. J., 15 (2009) 11346-11360. [49] P.D.W. Boyd, L.J. Wright, M.N. Zafar, Extending the Range of Neutral N-Donor Ligands Available for Metal Catalysts: N-[1-Alkylpyridin-4(1H)-ylidene]amides in Palladium-Catalyzed Cross-Coupling Reactions, Inorg. Chem., 50 (2011) 10522-10524. 
[50] K.F. Donnelly, C. Segarra, L.-X. Shao, R. Suen, H. Müller-Bunz, M. Albrecht, Adaptive NMesoionic Ligands Anchored to a Triazolylidene for Ruthenium-Mediated (De)Hydrogenation Catalysis, Organometallics, 34 (2015) 4076-4084.

[51] V. Leigh, D.J. Carleton, J. Olguin, H. Mueller-Bunz, L.J. Wright, M. Albrecht, SolventDependent Switch of Ligand Donor Ability and Catalytic Activity of Ruthenium(II) Complexes Containing Pyridinylidene Amide (PYA) N-Heterocyclic Carbene Hybrid Ligands, Inorg. Chem., 53 (2014) 8054-8060.

[52] M. Navarro, C.A. Smith, M. Albrecht, Enhanced Catalytic Activity of Iridium(III) Complexes by Facile Modification of C,N-Bidentate Chelating Pyridylideneamide Ligands, Inorg. Chem., 56 (2017) 11688-11701.

[53] M. Navarro, M. Li, H. Müller-Bunz, S. Bernhard, M. Albrecht, Donor-Flexible Nitrogen Ligands for Efficient Iridium-Catalyzed Water Oxidation Catalysis, Chem. Eur. J., 22 (2016) 6740-6745.

[54] M. Navarro, C.A. Smith, M. Li, S. Bernhard, M. Albrecht, Optimization of Synthetically Versatile Pyridylidene Amide Ligands for Efficient Iridium-Catalyzed Water Oxidation, Chem. Eur. J., 24 (2018) 6386-6398.

[55] P. Melle, Y. Manoharan, M. Albrecht, Modular Pincer-type Pyridylidene Amide Ruthenium(II) Complexes for Efficient Transfer Hydrogenation Catalysis, Inorg. Chem., 57 (2018) 11761-11774.

[56] M. Navarro, M. Li, S. Bernhard, M. Albrecht, A mesoionic nitrogen-donor ligand: structure, iridium coordination, and catalytic effects, Dalton Trans., 47 (2018) 659-662. [57] pp. Further details on data collection and refinement parameters are compiled in Tables S1. Crystallographic data for the structure have been deposited with the Cambridge Crystallographic Data Centre (CCDC) as supplementary publication number 19182143098. . [58] N.M. Simon, M. Zanatta, F.P. dos Santos, M.C. Corvo, E.J. Cabrita, J. Dupont, Carbon Dioxide Capture by Aqueous Ionic Liquid Solutions, ChemSusChem, 10 (2017) 4927-4933. [59] M. Zanatta, J. Dupont, G.N. Wentz, F.P. dos Santos, Intermolecular hydrogen bonds in water@IL supramolecular complexes, Phys. Chem. Chem. Phys., 20 (2018) 11608-11614. [60] M. Zanatta, A.-L. Girard, G. Marin, G. Ebeling, F.P. dos Santos, C. Valsecchi, H. Stassen, P.R. Livotto, W. Lewis, J. Dupont, Confined water in imidazolium based ionic liquids: a supramolecular guest@host complex case, Phys. Chem. Chem. Phys., 18 (2016) 1829718304.

[61] Y. Hiraga, Y. Sato, R.L. Smith, Development of a simple method for predicting CO2 enhancement of $\mathrm{H} 2$ gas solubility in ionic liquids, J. Supercrit. Fluids, 96 (2015) 162-170. [62] Z.K. Lopez-Castillo, S.N.V.K. Aki, M.A. Stadtherr, J.F. Brennecke, Enhanced Solubility of Hydrogen in CO2-Expanded Liquids, Ind. Eng. Chem. Res., 47 (2008) 570-576.

[63] Currently we are investigating the formation and reactivity of catalytic intermediates of the complexes investigated here using high pressure NMR techniques. Although the spectra are not entirely conclusive, the preliminary results exhibit hydridic species in the range of 11 ppm to -15 ppm with complex 3 under 60 bar pressure of $\mathrm{H}_{2}$. See $\mathrm{SI}$ for more details. [64] B. Mondal, F. Neese, S. Ye, Control in the Rate-Determining Step Provides a Promising Strategy To Develop New Catalysts for CO2 Hydrogenation: A Local Pair Natural Orbital Coupled Cluster Theory Study, Inorg. Chem., 54 (2015) 7192-7198.

[65] K.M. Waldie, A.L. Ostericher, M.H. Reineke, A.F. Sasayama, C.P. Kubiak, Hydricity of Transition-Metal Hydrides: Thermodynamic Considerations for CO2 Reduction, ACS Catal., 8 (2018) 1313-1324. 
[66] Y. Matsubara, E. Fujita, M.D. Doherty, J.T. Muckerman, C. Creutz, Thermodynamic and Kinetic Hydricity of Ruthenium(II) Hydride Complexes, J. Am. Chem. Soc., 134 (2012) 1574315757.

[67] B. Mondal, F. Neese, S. Ye, Toward Rational Design of 3d Transition Metal Catalysts for CO2 Hydrogenation Based on Insights into Hydricity-Controlled Rate-Determining Steps, Inorg. Chem., 55 (2016) 5438-5444.

[68] The different dependence of 2 and 2-MeCN suggest distinct differences of the two complexes for either $\mathrm{CO}_{2}$ bonding or $\mathrm{CO}_{2}$ insertion, and hence not the same catalytically active species. Tentatively, we suggest that the relevant $\mathrm{Ru}-\mathrm{H}$ species is formed via cymene dissociation, while the spectator ligand ( $\mathrm{Cl}-$ and $\mathrm{MeCN}$; respectively) remain bound and modulate the reactivity of the Ru center and of the $\mathrm{Ru}-\mathrm{H}$ bond. Evidence of this is shown in the SI.

[69] S.-M. Lu, Z. Wang, J. Li, J. Xiao, C. Li, Base-free hydrogenation of CO2 to formic acid in water with an iridium complex bearing a N,N[prime or minute]-diimine ligand, Green Chem., 18 (2016) 4553-4558.

[70] M.K. Diedrich, F.-G. Klärner, The Effect of Pressure on Cyclizations. The Ring-Size Dependent Reaction Volumes of the Cyclization of 1-Alkenes to Cycloalkanes. Experimental Measurement of Activation and Reaction Volumes of the Intramolecular Diels-Alder Reaction of 1,3,8-Nonatriene and 1,3,9-Decatriene. Temperature Dependence of Activation and Reaction Volumes, J. Am. Chem. Soc., 120 (1998) 6212-6218.

[71] J.E. Heimann, W.H. Bernskoetter, N. Hazari, James M. Mayer, Acceleration of CO2 insertion into metal hydrides: ligand, Lewis acid, and solvent effects on reaction kinetics, Chem. Sci., 9 (2018) 6629-6638.

[72] N. Hazari, J.E. Heimann, Carbon Dioxide Insertion into Group 9 and 10 Metal-Element $\sigma$ Bonds, Inorg. Chem., 56 (2017) 13655-13678.

[73] Distinct oxidation processes were only detectable in MeNO2. When using DMSO as a solvent, the oxidation of complexes $2-\mathrm{MeCN}$ and 3 was poorly resolved and not suitable for determining a redox potential (Figures S7-S8).

[74] E.S. Wiedner, M.B. Chambers, C.L. Pitman, R.M. Bullock, A.J.M. Miller, A.M. Appel, Thermodynamic Hydricity of Transition Metal Hydrides, Chem. Rev., 116 (2016) 8655-8692. [75] B.R. Galan, J. Schöffel, J.C. Linehan, C. Seu, A.M. Appel, J.A.S. Roberts, M.L. Helm, U.J. Kilgore, J.Y. Yang, D.L. DuBois, C.P. Kubiak, Electrocatalytic Oxidation of Formate by [Ni(PR2NR'2)2(CH3CN)]2+ Complexes, J. Am. Chem. Soc., 133 (2011) 12767-12779. [76] A.M. Lilio, M.H. Reineke, C.E. Moore, A.L. Rheingold, M.K. Takase, C.P. Kubiak, Incorporation of Pendant Bases into Rh(diphosphine)2 Complexes: Synthesis, Thermodynamic Studies, And Catalytic CO2 Hydrogenation Activity of [Rh(P2N2)2]+ Complexes, J. Am. Chem. Soc., 137 (2015) 8251-8260.

[77] K.M. Waldie, F.M. Brunner, C.P. Kubiak, Transition Metal Hydride Catalysts for Sustainable Interconversion of $\mathrm{CO} 2$ and Formate: Thermodynamic and Mechanistic Considerations, ACS Sus. Chem. Eng., 6 (2018) 6841-6848.

[78] C.L. Pitman, K.R. Brereton, A.J.M. Miller, Aqueous Hydricity of Late Metal Catalysts as a Continuum Tuned by Ligands and the Medium, J. Am. Chem. Soc., 138 (2016) 2252-2260.

[79] G. Kubas, Metal-dihydrogen and $\sigma$-bond coordination: The consummate extension of the Dewar-Chatt-Duncanson model for metal-olefin $\pi$ bonding, 2001.

[80] T. Ono, S. Qu, C. Gimbert-Suriñach, M.A. Johnson, D.J. Marell, J. Benet-Buchholz, C.J. Cramer, A. Llobet, Hydrogenative Carbon Dioxide Reduction Catalyzed by Mononuclear 
Ruthenium Polypyridyl Complexes: Discerning between Electronic and Steric Effects, ACS Catal., 7 (2017) 5932-5940.

[81] B.L. Thompson, Z.M. Heiden, Investigation of main group promoted carbon dioxide reduction, Tetrahedron, 75 (2019) 2099-2105. 